\begin{tabular}{|l|l|}
\hline & \\
\hline
\end{tabular}

SEÇÃO:

\title{
Educação sob um olhar antirracista na formação escolar da Amazônia brasileira
}

\author{
Education under an antiracist look at school training in the brazilian Amazon \\ Educación bajo una mirada antirracista en la formación escolar de la Amazonía \\ brasileña
}

\section{Andrelize Schabo \\ Ferreira de Assis ${ }^{1}$}

orcid.org/0000-0002-4273-3857

andrelizeschabo@gmail.com

\section{Kátia Sebastiana}

Carvalho dos Santos

Farias $^{1}$

orcid.org/0000-0001-5646-8604

katiafarias@unir.br

Recebido em: 18 dez. 2018. Aprovado em: 26 jan. 2021. Publicado em: 21 jun. 2021.
Resumo: O objetivo deste texto é problematizar o trabalho desenvolvido sobre a temática racial em uma instituição pública de ensino na Amazônia, com foco na tensão entre o multiculturalismo funcional e a interculturalidade crítica. Os diálogos ficcionais dos jogos de cenas, inspirados na terapia desconstrucionista de Jacques Derrida (1971) e nos jogos de linguagem de Ludwig Wittgenstein (2014), mostram que há diferentes maneiras de se trabalhar educação antirracista em sala de aula e que é importante compreender alguns conceitos sobre a temática para evitar, nos termos de Veiga-Neto (2003), o multiculturalismo bom-mocista, que mantém intactas as bases hierarquicamente racializadas da sociedade brasileira. Confrontar e discutir criticamente o racismo é responsabilidade de todos, especialmente dos envolvidos no processo de formação escolar e acadêmica. Palavras-chave: discriminação étnica, educação antirracista, jogos de cenas

Abstract: The objective of this text is to problematize the work developed on the racial theme in a public educational institution in the Amazon, focusing on the tension between functional multiculturalism and critical interculturality. The fictional dialogues of games of scenes, inspired by Jacques Derrida's deconstructionist therapy (1971) and Ludwig Wittgenstein's language games (2014), show that there are different ways of working with anti-racist education in the classroom and that it is important to understand some concepts on the subject to avoid, in the terms of Veiga-Neto (2003), the hypocritical multiculturalism, which keeps intact the hierarchically racialized bases of Brazilian society. Confronting and critically discussing racism is the responsibility of everyone, especially those involved in the process of school and academic education.

Keyword: ethnic discrimination, anti-racist education, games of scenes

Resumen: El objetivo de este texto es problematizar el trabajo desarrollado sobre el tema racial en una institución educativa pública en la Amazonía, enfocándose en la tensión entre el multiculturalismo funcional y la interculturalidad crítica. Los diálogos ficticios de los juegos de escenas, inspirados en la terapia deconstruccionista de Jacques Derrida (1971) y los juegos de lenguaje de Ludwig Wittgenstein (2014), muestran que hay diferentes formas de trabajar con la educación antirracista en el aula y que es importante comprender algunos conceptos sobre el tema para evitar, en los términos de Veiga-Neto (2003), el multiculturalismo hipócrita, que mantiene intactas las bases jerárquicamente racializadas de la sociedad brasileña. Enfrentar y discutir criticamente el racismo es responsabilidad de todos, especialmente de aquellos involucrados en el proceso de educación escolar y académica.

Palabras clave: discriminación étnica, educación antirracista, juegos de escenas 
Discutir racismo e educação antirracista é desafiador e nos remete aos fatos históricos que estruturaram as desigualdades na sociedade brasileira ao longo dos séculos, impedindo determinados grupos étnico-raciais de ter acesso a espaços majoritariamente brancos; bem como nos remete também a informações e dados contemporâneos, que mostram como essas desigualdades se manifestam na sociedade brasileira na atualidade.

Estudos publicados em 2019 pela Diretoria de Pesquisa, Coordenação de População e Indicadores Sociais do Instituto Brasileiro de Geografia e Estatística (IBGE) apontam que 68,6\% dos cargos gerenciais no Brasil são ocupados por brancos, enquanto apenas 29,9\% são ocupados por negros (autodeclarados pretos e pardos); bem como a taxa de analfabetismo dos negros é mais que o dobro do que a dos brancos e, além disso, a taxa de homicídios a cada 100 mil jovens também é maior entre negros $(98,5)$ do que entre brancos $(34,0)$. Esses e outros dados oficiais comprovam que há uma grande desigualdade entre negros e brancos no país, fruto de mais de três séculos de escravidão em que o Brasilé marcado por ser o último país da América Ocidental a abolir o escravismo.

Também é importante lembrar que no país tivemos ações afirmativas para brancos, como, por exemplo, a Lei de Terras de 1850, que incentivou a vinda para o Brasil de imigrantes europeus, dando início à elite latifundiária do país. Essa lei e outras ações voltadas ao embranquecimento da população faziam parte de um projeto político que tinha como base ideológica a associação racista de que os negros representavam atraso. Nesse sentido, no processo pós-abolição não foram planejadas ações de reintegração na sociedade para as pessoas negras, o que explica muitas das desigualdades sociais que se estruturaram como raciais. Destacamos que o racismo é um termo que possui pelo menos três concepções (individualista, institucional e estrutural), porém, ao abordamos a importância da educação antirracista nas instituições escolares partimos do fato de que o racismo é um problema estrutural na sociedade brasileira. Sendo assim,
(...) consciente de que o racismo é parte da estrutura social e, por isso, não necessita de intenção para se manifestar, por mais que calar-se diante do racismo não faça do individuo moral e/ou juridicamente culpado ou responsável, certamente o silêncio o torna ética e politicamente responsável pela manutenção do racismo. A mudança da sociedade não se faz apenas com denúncias ou com o repúdio moral do racismo: depende, antes de tudo, da tomada de posturas e da adoção de práticas anti-racistas. (Almeida, 2019, p. 52)

Pensar em uma educação não eurocêntrica e antirracista é entender, inspirando-nos em Ângela Davis, que "em uma sociedade racista, não basta não ser racista, é preciso ser antirracista" (Muniz, 2019). Isso implica o envolvimento da escola com vistas a abrir-se para a problematização do mundo, confrontando aquela "educação orientada por desejos de unidade, consenso, unidade na diversidade e inclusão da diversidade na grande meta-narrativa do discurso liberal significa colonização liberal" (Farias, 2019, p. 1). Em entrevista à Chérif Mustapha, disponivel na obra O islã e o Ocidente (2013), Jacques Derrida afirma que a pluralidade, a alteridade, o princípio das diferenças e a necessidade do respeito pela alteridade estão nos principios da civilização. "Logo, não imagino uma civilização universal homogênea, seria o contrário de uma civilização" (Mustapha, 2013, p. 86). E adverte que:

Os desafios nunca foram tão graves quanto
no mundo de hoje; são desafios novos, que
pedem uma nova reflexão sobre o que pode
querer dizer e ser universal. Apelo ao direito
de colocar questões criticas, não somente à
história deste ou daquele conceito, mas tam-
bém à história da noção de crítica, à forma
interrogativa do pensamento (...) O risco de
agravamento das desigualdades e da desu-
manização é um dos traços de nossa época.
(Mustapha, 2013, p. 87-88)

Indo ao encontro desse pensamento, entendemos que é importante e necessário no ambiente escolar questionar o conceito de raça, sua ficcionalidade e sua operacionalidade na sociedade atual, porém, sem deixar de lado a crítica sobre os padrões coloniais que moldam nossas maneiras de agir, de ver e de pensar a respeito das problemáticas que nos cercam. Esse movimento exige comprometimento dos 
educadores e de toda a comunidade escolar, pois para interromper a reprodução dos padrões eurocêntricos e coloniais aos quais estamos submetidos é preciso compreender os mecanismos de sua perpetuação - tais como o multiculturalismo funcional. Entendemos que "a escola ainda é o espaço fundamental de produção de conhecimento crítico, desde que a entendamos, também, como o lócus onde as problemáticas do contexto histórico e social se materializam" (Silva, 2010, p. 222). Por fim, recorremos a Sartre (1968) para ilustrar os apontamentos que virão nas próximas páginas: "É necessário que nós (...) nos descolonizemos, isto é, extirpemos, por meio de uma operação sangrenta, o colono que há em cada um de nós. Examinemo-nos, se tivermos coragem, e vejamos o que se passa conosco" (Sartre, 1968, p. 16).

\section{Multiculturalismo bom-mocista: uma pedra no caminho?}

A inspiração para escrever esse texto ocorreu após observarmos em uma instituição pública de ensino na Amazônia que o trabalho com a diversidade e o multiculturalismo em sala de aula, muitas vezes, apresenta um aspecto funcional, ou, nos termos de Veiga-Neto, um multiculturalismo bom-mocista, que mantém intactas e, até mesmo, reforça as bases hierarquicamente racializadas da sociedade brasileira, além de confundir desigualdade com diferença. Segundo ele:

(...) essa história de aceitar a diferença pode estar carregando uma boa dose de tolerância benigna, de "bom-mocismo", de "bom-samaritanismo", posturas éticas que, como sabemos, são conservadoras e servem para encobrir e, por isso, reforçar e perpetuar a própria desigualdade. (Veiga-Neto, 2003, p. 212)

O autor questiona a tendência de alguns movimentos e propostas escolares que partem da confusão entre os conceitos de diferença e de desigualdade. De acordo com Veiga-Neto (2003), a ideia de que a convivência ensina a aceitar o diferente advém de uma lógica de que a familiaridade é o elemento-chave para a aceitação, que garantiria um convívio social harmônico e cooperativo. No caso da instituição pesquisada por nós, observamos por meio de conversas em dois encontros realizados com quatro professores que a questão das diferenças, muitas vezes, é equivocadamente abordada nesse sentido de aceitar e de tolerar os diferentes.

Destacamos que esse trabalho é realizado pelos professores com vistas a uma educação antirracista e que é uma prática muito comum e propagada nas escolas. No entanto, tolerar é um termo que carrega em seus usos um binarismo e uma hierarquização onde o superior tolera o inferior, pois quando se tolera algo, é porque é ruim. Veiga-Neto (2003) destaca que a confusão entre desigualdade e diferença pode levar a tentativas de anular a diferença, levando à colonização e à anulação do outro. Esse movimento de anular as diferenças, geralmente, ocorre de três formas, segundo o autor: ou se transforma o outro (anulando o que ele tem dele mesmo); ou se faz do outro um simulacro mantendo-o no ridiculo; ou se elimina o outro. Destacamos que a diferença não deve ser tolerada, pois não é ruim, ela deve ser celebrada e valorizada. Reforçamos também que desigualdade e diferença são conceitos que não podem ser confundidos ou tratados como sinônimos ao trabalhar a temática racial, pois a desigualdade deve ser combatida com vistas ao seu desaparecimento, porém as diferenças devem ser estimuladas e utilizadas em prol do enriquecimento do aprendizado no contexto educacional.

Nesse sentido, destacamos que o multiculturalismo não é uma única doutrina e que ele pode ser conservador, liberal, comercial, corporativo, crítico, dentre outros, por essa razão não podemos cair na armadilha de discursos que, apesar de aparentemente positivos, são funcionais ao racismo estrutural brasileiro. Além disso, ainda há uma espécie de daltonismo no Brasil, tema explorado por Jesus Junior (2002), que explica a tendência de se encarar a temática racial no Brasil com referência a problemas do outro, do negro, considerado o diferente em contraposição ao universal, o branco. Bento (2002, p. 41) mostra-nos que "esse daltonismo e cegueira caracterizam um estranho funcionamento de nossos cientistas e estudiosos, 
que conseguem investigar, problematizar e teorizar (...) de forma completamente alienada da história dessa sociedade". É preciso marcar as estruturas das relações raciais e identificar os papéis dos brancos na manutenção do sistema racista.

Nessa temática que enfrenta tantos mitos e conceitos equivocados, é importante combater não só o racismo, mas também o achismo, como nos mostra Ribeiro (2017), pois muito se acha sobre a temática, porém precisamos combater estes mitos um por um com conhecimento e informação. O daltonismo, o mito da mestiçagem, o mito da democracia racial, o mito da meritocracia, enfim, são muitas as estratégias de deslegitimização da luta contra o racismo no Brasil.

Enquanto educadores, atuar criticamente envolve questionar a formação da estrutura racializada da sociedade, mobilizando os estudantes a compreender desde as raízes históricas da formação da identidade a partir de quem detinha o poder de defini-la, até a operacionalidade das raças na atualidade, a partir de sua colonialidade e ficcionalidade e, também, de como o conceito raça vem se transformando ao longo das décadas e se ressignificando.

A interculturalidade crítica surge para nos mostrar que é preciso questionar e intervir na colonialidade a qual estamos submersos, dialogando com modos e formas de vida diversos sem impor hierarquicamente uma maneira de ver e pensar de uma cultura sobre a outra, respeitando suas autonomias e riquezas. A interculturalidade critica busca combater as desigualdades de baixo para cima, a partir dos agentes do movimento indigena que sofrem com essa subalternização, mas amplia-se para o conjunto da sociedade, o que:

(...) é significativo, tanto pela diferença que marca com o projeto hegemônico dominante e sua ideia de que os indígenas só se preocupam consigo mesmos, como pela aposta, proposta e projeto diferentes que sugerem. É esse movimento que amplia e envolve 'em aliança' setores que, da mesma forma, buscam alternativas à globalização neoliberal e à racionalidade ocidental, e que lutam tanto pela transformação social como para a criação de condições de poder, saber e ser muito diferentes. Pensada dessa maneira, a interculturalidade crítica não é um processo ou um projeto étnico, nem tampouco um projeto da diferença em si. Antes, e como argumenta Adolfo Albán (2008), é um projeto que aponta à reexistência e à própria vida, para um imaginário 'outro' e uma agência 'outra' de com-vivência - de viver 'com' - e de sociedade. (Walsh, 2009, p. 22)

Esse movimento é interessante e tem muito a nos ensinar, pois a colonialidade, como nos mostra Maldonado-Torres (2007), é um padrão de poder que advém do colonialismo moderno e se relaciona ao modo como o trabalho, o conhecimento, a autoridade e demais relações se articulam sobre a ideia de raça. Segundo o autor, a colonialidade afeta a autoimagem dos povos, as aspirações dos sujeitos, os critérios para distinguir o bom do ruim, o belo do feio, dentre tantos outros aspectos do mundo moderno. Nesse sentido, pensar em práticas descolonizadoras é romper com movimentos em que "busca-se promover o diálogo e a tolerância sem tocar nas causas da assimetria social e cultural hoje vigentes, enquanto no interculturalismo crítico busca-se suprimi-las por métodos políticos não violentos" (Tubino, 2005, p. 8).

Respondendo ao título desse tópico, o multiculturalismo bom-mocista tem se colocado como uma pedra no caminho para a educação antirracista, pois caracteriza-se por essa tentativa falha de promover a tolerância e a aceitação sem discutir e confrontar as causas das assimetrias culturais e sociais brasileiras, reproduzindo e reforçando a colonialidade e, consequentemente, as desigualdades na sociedade. No entanto:

(...) ao contrário de ontologicamente necessárias, essas dificuldades são contingentes. Entendê-las como contingentes - isso é, entendê-las como resultado de múltiplos arranjos históricos cuja tecitura, uma vez conhecida, pode eventualmente ser alterada, redirecionada, rompida - não faz delas um obstáculo menos poderoso para as transformações sociais que se queira fazer". (Veiga-Neto, 2001b, p. 25)

Nesse sentido, parafraseando Carlos Drummond de Andrade (1930), essa pedra no caminho não pode nos impedir de avançar em prol de uma educação antirracista. Que nunca nos esqueçamos, apesar de nossas "retinas tão fatigadas" da nossa responsabilidade diária e constante na luta contra o racismo. 


\section{Antirracismo na educação: olhares e propostas}

Ao tratar a temática racial é importante destacar que é cruel e desonesta a tentativa de usurpar o lugar de fala do outro. Contudo, como bem orienta Ribeiro (2017), todos possuímos lugar de fala, porém partimos de pontos diferentes. Mobilizamos esse conceito, pois é comum ouvirmos pessoas brancas, na tentativa de se isentarem de sua responsabilidade no combate a práticas racistas, afirmarem que como não são negras estariam usurpando o lugar de fala do outro, mas o racismo precisa ser encarado de frente por todos na sociedade. Por isso:

\begin{abstract}
Mais um equívoco a superar é a crença de que a discussão sobre a questão racial se limita ao Movimento Negro e a estudiosos do tema e não à escola. A escola, enquanto instituição social responsável por assegurar o direito da educação a todo e qualquer cidadão, deverá se posicionar politicamente, como já vimos, contra toda e qualquer forma de discriminação. A luta pela superação do racismo e da discriminação racial é, pois, tarefa de todo e qualquer educador, independentemente do seu pertencimento étnico-racial, crença religiosa ou posição política. O racismo, segundo o Artigo $5^{\circ}$ da Constituição Brasileira, é crime inafiançável e isso se aplica a todos os cidadãos e instituições, inclusive, à escola. (Brasil, 2004, p. 16)
\end{abstract}

Nesse sentido, é preciso pensar em práticas voltadas para uma educação antirracista, tendo em vista que "se a educação sozinha, não transforma a sociedade, sem ela tampouco a sociedade muda" (Freire, 2000, p. 67). A partir desse momento, inspirados nos modos de filosofar de Jacques Derrida e Ludwig Wittgenstein, percorreremos um percurso investigativo terapêutico-gramatical desconstrucionista por meio de jogos de cenas que:

(...) não reivindica à própria narrativa o estatuto epistêmico de "saber" ou de "conhecimento", ou então, de 'novos' saberes ou 'novos' conhecimentos "acerca de...". Menos pretensiosamente, encara tal narrativa meramente como um relato potencialmente capaz de gerar nos corpos de seus leitores efeitos de sentido que lhes permitam realizar seus próprios percursos terapêuticos idiossincráticos dos problemas, propósitos, expectativas e crenças que os con- duziram à leitura da narrativa produzida pelo investigador terapeuta. (Miguel, 2015, p. 638)

Por isso, esses olhares e propostas sobre educação antirracista apresentam-se por meio de jogos de cenas justamente para romper com as formas dogmáticas e eurocêntricas de se praticar pesquisas, mobilizando outras possibilidades. Os diálogos narrados são chamados por nós de ficcionais, mas "têm ocorrência efetiva a partir de eventos efetivos, de documentos pesquisados, entrevistas realizadas, dentre outras ocorrências que constituem o ato de pesquisar" (Marim \& Farias, 2017, p. 179). As falas dos professores, visando compor o encadeamento dos jogos de cenas, são enxertadas de outros textos que compõem a pesquisa de Assis (2019), pois “(...) o enxerto é a própria figura da intervenção. A prática da enxertia textual opera '(...) explorando a iterabilidade da língua, sua capacidade de funcionar em novos contextos com nova força'" (Farias \& Moura, 2019, p. 89).

Este estilo, os jogos de cenas, quando usado como estratégia de narrar e performar textos científicos-acadêmicos leva para a rede de discussões da casa o embate gerado pelo natural enfeitiçamento provocado pela concepção clássica de linguagem, em suas distinções e definições, como exemplo: este texto é científico ou literário? É uma escrita fictícia ou efetiva? É verdadeiro ou falso? Dentre essas e outras ontologias e categorizações que chacoalham essa rede suspensa que pode se distender, para então, dar espaço para que outras dobras e tramas componham o seu balançar (Marim \& Farias, 2017, p. 178).

No recorte de cena abaixo, constam trechos das problematizações levadas para um encontro realizado com quatro professores ${ }^{3}$ de uma instituição de ensino pública na Amazônia. Optamos por preservar a identidade dos participantes, por isso seus nomes são inspirados em personalidades engajadas na luta contra o racismo no Brasil. A pesquisadora apresenta-se como Elisa (Larkin) e os professores participantes como Nelson (Mandela), Dandara (dos Palmares), Mariele

3 Comunicações pessoais, 23 set. 2019. 
(Marielle Franco) e Carolina (de Jesus). Os cinco personagens conversam entre si sobre práticas e posturas em sala de aula com vistas a uma educação antirracista, em que se desnaturalize conceitos estabelecidos que reproduzem ideologias que reforçam a desigualdade.

O encontro narrado abaixo ocorreu em uma tarde chuvosa de setembro de 2019, momento de transição para a estação que corresponde ao inverno amazônico. Os professores foram chegando aos poucos e se acomodando nas carteiras escolares de uma sala de aula ampla, que continhaum quadro branco grande e uma mesa ao centro com computador, onde Elisa estava sentada aguardando-os.

Elisa - (Inicia a conversa sobre a temática). Sei que nem todos tiveram formação para trabalhar com a diversidade em sala de aula e que "(...) essa falta de preparo, que devemos considerar como reflexo do nosso mito de democracia racial, compromete, sem dúvida, o objetivo fundamental da nossa missão no processo de formação dos futuros cidadãos responsáveis de amanhã. Com efeito, sem assumir nenhum complexo de culpa, não podemos esquecer que somos produtos de uma educação eurocêntrica e que podemos, em função desta, reproduzir consciente ou inconscientemente os preconceitos que permeiam nossa sociedade" (Munanga, 2005, p. 15).

Professor Nelson - (De forma simpática, questiona Elisa). Na sua visão, o que faz com que até hoje haja esse eurocentrismo nos textos, livros, filmes... Enfim... Em tudo que consumimos?

Professora Dandara - (Concordando com a cabeça). Boa pergunta, Nelson! Até porque, "do ponto de vista cultural ou simbólico, um aspecto fundamental de nossa sociedade tem sido o racismo que, como tudo indica, origina-se do eurocentrismo" (Silvério, 2003, p. 66).

Elisa - (Responde prontamente). A colonialidade em que estamos mergulhados! Diferente do colonialismo, a colonialidade é resultado dele. e se refere à "forma como o trabalho, o conhecimento, a autoridade e as relações intersubjetivas se articulam entre si através do mercado capitalista mundial e da ideia de raça. (...) A colonialidade se mantém viva nos textos didáticos, nos critérios para o bom trabalho acadêmico, na cultura, no senso comum, na autoimagem dos povos, nas aspirações dos sujeitos e em muitos outros aspectos de nossa experiência moderna" (Maldonado-Torres, 2007, p. 131).

Professor Nelson - (Concordando com a cabeça). E por meio dela ainda há a inferiorização do que não é europeu, o eurocentrismo é colonialidade do poder. Sabemos que "a superação do racismo ainda presente em nossa sociedade é um imperativo. É uma necessidade moral e uma tarefa politica de primeira grandeza. E a educação é um dos terrenos mais decisivos para que sejamos vitoriosos nesse esforço" (Munanga, 2005, p. 10), porém, há muitos entendimentos diferentes sobre essa temática... É difícil encontrar convergência.

Elisa - (Concorda, olhando para Nelson). Realmente, professor! Pensando em uma educação antirracista, há pelo menos quatro principais visões diferentes: "A primeira delas é aferrar-se a crenças racialistas (ou seja, crenças na determinação biológica de qualidades morais, psicológicas e intelectuais, ao longo da transmissão de caracteres fenotípicos que definem 'raças')" (Guimarães, 2002, p. 51).

Professora Mariele - (Interrompe, com expressão de espanto). Como é que é? Então eles aceitam as diferenças entre as raças?

Elisa - (Continua explicando, segurando o texto de Guimarães). Bem, segundo Guimarães (2002, p. 52), essa postura antirracista "tem bases delicadas, uma vez que aceita diferenças de qualidades e de propriedades raciais sem que aceite a hierarquia entre elas". Aqui no Brasil essa postura não é muito popular...

Professora Mariele - (Franzindo a testa, comenta). Não me parece muito "científica", se posso falar assim. Eu não acredito em raças humanas no sentido biológico, para mim é um conceito social. São "raças sociais", por assim dizer, que dificilmente serão superadas na sociedade como ela é.

Elisa - (Comenta, olhando para Mariele). Então, essa é a segunda postura sobre a qual vou falar, Mariele. "(...) as pessoas que adotam tal postura antirracista, também não acreditam em raças biológicas, mas aceitam que as raças sociais são construções sociais permanentes, sobre as quais se deve organizar a luta antirracista" (Guimarães, 2002, p. 52).

Professora Dandara - (Complementa). É complicado acreditar em algo "insuperável", ou até mesmo "permanente" nesses tempos líquidos em que vivemos...

Elisa - (Concordando com a cabeça) É, fora essas duas, há mais outras duas posturas que implicam na superação da ideia das raças. Uma acredita que já que as raças são construções, do ponto de vista científico e social, que precisam ser superadas para que se erradique o racismo. Segundo esse pensamento, a ideia de raça inevitavelmente conduz ao racismo... ${ }^{4}$

Professor Nelson - (Com expressão pensativa). Estou aqui pensando em qual postura antirracista meu trabalho em sala se encaixaria... Ainda não saberia dizer.

\footnotetext{
4 "(...) como nos ensina Hasenbalg (1977), a raça tem sido um critério adscritivo conscientemente mantido pelos brancos simplesmente porque os mesmos mantêm vantagens materiais e simbólicas" (Silvério, 2003, p. 66).
} 
Elisa - (Continua, empolgada). Ainda há mais uma! A quarta possibilidade, à qual Guimarães (2002) e eu nos filiamos, passa por dois passos: o primeiro é o reconhecer a inexistência das raças biológicas; e o segundo é reconhecer a constante transformação da raça sob diferentes formas.

Professora Mariele - (Complementa) Realmente o simples não racialismo não garante o antirracismo, mas é interessante perceber que todas as posturas passam pelo conhecimento, pelo saber.

Elisa - (Sorrindo, continua). Esse é ponto mais importante. As posturas antirracistas, até mesmo as que mantêm o conceito de raça, partem da necessidade de uma compreensão basilar para a superação do racismo: não há hierarquia entre as "raças".

Professora Dandara - (Complementa). Como eu disse, o berço histórico de surgimento do termo é a modernidade europeia, o desenvolvimento da ciência ao longo da colonização e a própria escravização dos povos africanos...

Elisa - (Completa). (...) Raça nunca foi um conceito estático, ele faz parte de um encadeamento de coisas inacabadas... Hoje há também o racismo sem raça, onde a cultura e a religião tomaram o lugar da "biologia".

Professora Dandara - (Complementa). (...) São muitas nuances... É como o racismo, muitas vezes falamos como se fosse uma coisa única indistintamente, mas o termo possui pelo menos três concepções: individualista, institucional e estrutural.

Professora Mariele - (Expressão de confusa). Sim, sei que o racismo individualista é ligado a aspectos comportamentais e práticas individuais. Entendo que a grande fragilidade dessa concepção é que não leva em consideração que muitas vezes as práticas racistas são feitas sob a legalidade e até mesmo apoio de líderes políticos e religiosos, não é algo restrito ao individuo. Mas, enfim, qual a diferença entre o racismo institucional e estrutural?

Professora Dandara - (Responde gentilmente, abrindo o livro "Racimo Estrutural"). Segundo Almeida (2019), o racismo institucional não se relaciona apenas a comportamentos individuais, mas é resultado do funcionamento das instituições, que passam a atuar em uma dinâmica que confere, ainda que indiretamente, desvantagens e privilégios com base na raça. O conceito de racismo estrutural vai além, ele não é visto como criado pela instituição, mas representado por ela...

Professor Nelson - (Corta e acrescenta). Nesse sentido, "consciente de que o racismo é parte da estrutura social e, por isso, não necessita de intenção para se manifestar, por mais que calar-se diante do racismo não faça do indivíduo moral e/ou juridicamente culpado ou responsável, certamente o silêncio o torna ética e politicamente responsável pela manutenção do racismo. A mudança da sociedade não se faz apenas com denúncias ou com o repúdio moral do racismo: depende, antes de tudo, da tomada de posturas e da adoção de práticas antirracistas" (Almeida, 2019, p. 52).

Professor Nelson - (Comenta). (...) Nesse sentido é que precisamos questionar e problematizar em sala de aula, não podemos pressupor que todos compreendem que não há um fundamento cientíico nas raças humanas. É importante discutir isso com os alunos.

Professora Mariele - (Concordando com a cabeça). (...) Concordo, a raça é tomada e pensada como algo natural. Muitos alunos até sabem que não tem fundamento biológico ou científico, mas não entendem a complexidade do termo. Discutir esse conceito pode contribuir para desnaturalizá-lo, desconstruí-lo, mostrando que foi construido social e discursivamente.

Professora Dandara - (Pensativa). Até porque, se pararmos para pensar, o racismo é um problema derivado da criação das raças que serviu para separar quem somos nós de quem são os outros.

Professora Mariele - (Comenta, problematizando). (...) Em sala de aula, é preciso pensar em um diálogo intercultural pós-colonial em que não ocorra a "(...) imposição unilateral de valores, formas de ver e pensar de uma cultura a outra, o que poderia assegurar a autonomia de cada forma de vida condicionada" (TamayoOsório, 2017, p. 40).

Professora Mariele - (Mostrando-se preocupada). É dificil sair do discurso. Vejo que muitas vezes não há esse olhar mais crítico em sala de aula no tocante ao trabalho com as diferenças... O resultado é que se reproduzem e até confundem-se conceitos.

Professor Nelson - (Complementa). A formação dos professores é importante, mas mesmo os que já têm formação muitas vezes sentem que faltam materiais mais direcionados também (...).

Professora Carolina - (Comenta criticamente). $\mathrm{Na}$ verdade, material tem e muito. Na internet eu encontro muita coisa relacionada ao tema, mas muito material que se limita mesmo ao papel de tolerar e aceitar as diferenças, nesse sentido do multiculturalismo bom-mocista... São conceitos que se confundem mesmo.

Elisa - (Acrescenta, complementando o que disse Carolina). E ele é uma "estratégia política funcional ao sistema/mundo moderno e ainda colonial; pretende 'incluir' os anteriormente excluidos dentro de um modelo globalizado de sociedade, regido não pelas pessoas, mas pelos interesses de mercado. Tal estratégia e política não buscam transformar as estruturas sociais racializadas; pelo contrário, seu objetivo é administrar a diversidade diante do que está visto como o perigo da radicalização de imaginários e agenciamentos étnicos" (Walsh, 2009, p. 20).

Professora Dandara - (Levanta a mão, pedindo a palavra). Quando comentou sobre estratégia política funcional, lembrei-me que "o apartheid (palavra do Afrikans) foi oficial- 
mente definido como um projeto político de desenvolvimento separado, baseado no respeito das diferenças étnicas ou culturais dos povos sul-africanos. Um projeto, certamente fundamentado no multiculturalismo político e ideologicamente manipulado" (Munanga, 2003, p. 10). (Assis, 2019, p. 134)

O encontro e as discussões continuam, porém, mobilizamos o recorte acima para ilustrar a preocupação que os professores possuem sobre a temática nessa instituição e os diferentes modos de se trabalhar educação antirracista. A postura antirracista a qual nos filiamos entende que não adianta simplesmente abolir o termo raça, pois mesmo após compreendermos que não há quaisquer fundamentos biológicos para raças humanas, "durante um bom tempo, precisaremos ainda usar a palavra "raça" de um modo analítico, para compreender o significado de certas classificações sociais e de certas orientações de ação informadas pela ideia de raça" (Guimarães, 2002, p. 53). Observamos, também, que por se tratar de um assunto complexo e abrangente, os docentes sentem necessidade de formação, mas compreendem que é preciso discutir a invenção das raças, pois saber como formou-se a situação atual é o primeiro passo para qualquer possibilidade de mudança. E assim, "ao invés de vivermos no trabalho político e messiânico de preparar a grande virada que nos levaria para um futuro melhor, feliz e definitivo (...) poderemos viver no permanente trabalho político (mas não messiânico) de promover a crítica radical e a insurreição constante" (Veiga-Neto, 2001a, p. 25).

\section{Algumas considerações}

Contrapondo-se aos estudos e às informações estatísticas, há um negacionismo que propaga que não há racismo no Brasil e que o país é uma democracia racial em que os negros possuem as mesmas oportunidades que os brancos. Essa afirmação contraria todas as estatísticas e ignora todo um contexto histórico marcado por mais de três séculos de escravidão. Lilian $M$. Schwarcz (2018) aponta em seus textos que o sistema escravagista moldou o Brasil, pois não só os grandes proprietários escravizavam, mas até mesmo pequenos profissionais da época. Havia também a escravidão conhecida como "de pequeno porte", onde as casas tinham amas de leites, meninos de recado etc.

A escravidão penetrou em todas as formas de trabalho. Nesse mesmo sentido, não há como falar de religião no Brasil sem nos remetermos às religiões de matriz africana, não há como falar de culinária e nem do cultivo do açúcar, por exemplo, sem pensar nas técnicas e nas contribuições africanas. No entanto, pouco ou nada disso é reconhecido. O que vemos, nas palavras de Tamayo-Osorio, é uma dieta unilateral, que invisibiliza essas contribuições em prol de influências europeias. Devido a isso, é importante trazer para a sala de aula outros autores, outros pontos de vista e outros saberes, diferentes dos cânones europeus, inclusive os que não estão necessariamente ligados à educação formal (pessoas sem um diploma formal, por exemplo, mas que tenham oportunidade de compartilhar seus saberes e que podem contribuir muito com os estudantes, tal como "O Encontro de Saberes", que atua nesse sentido na UnB desde 2010).

Nesse sentido, os efeitos do multiculturalismo bom-mocista no ambiente escolar perpetuam e reforçam a hierarquização em que o superior tolera o inferior e não contribui para a desconstrução de práticas racistas. Compreender o conceito de raça, suas origens enquanto termo ficcional (e não biológico) e o seu papel na sociedade atual é necessário, pois, além de respeitar as diferenças, deve-se celebrá-las por trazerem consigo múltiplos saberes e pontos de vista à escola, enriquecendo os estudos, a vida e descolonizando o saber.

No decorrer da pesquisa, entendemos que antes de adentrar nesse viés da educação antirracista é necessário abordar alguns conceitos como, por exemplo, os tipos de multiculturalismo, os tipos de racismo, o conceito de colonialismo, de colonialidade, de decolonialidade, dentre outras temáticas que foram trabalhadas na formação realizada com os professores interessados e nas conversas com os participantes da pesquisa. É uma temática bastante ampla e que não se exaure em 
uma formação, pois exige estudo e dedicação, mas o primeiro passo foi dado nesse sentido. Muitas vezes, os brancos são levados a se enxergarem como universal, no sentido de ser o padrão do qual os demais divergem. Ao compreender e questionar a origem disso, muitos conceitos vão se desconstruindo. Nesse sentido, mobilizo Grada Kilomba em entrevista concedida a Ribeiro (2018), que afirma que parte do processo de descolonização é produzir perguntas que fragmentam certezas.

É compreensivel que em um país fundado no mito da democracia racial seja difícil para algumas pessoas compreenderem e aceitarem que há racismo na nossa sociedade, o que seria o pontapé para tornar-se antirracista. Assim, entende-se que a educação antirracista é importante no ambiente escolar para que se discuta a formação da identidade, o ponto a partir do qual houve a marcação das diferenças, a formação e a transformação do conceito de raças, e, por fim, a desmistificação da hierarquização entre elas. A partir do pensamento crítico, formar cidadãos capazes de compreender esse complexo contexto histórico e social, debatendo o racismo e atuando de forma antirracista em todos os espaços.

\section{Referências}

Almeida, S. L. de. (2019). Racismo Estrutural. São Paulo: Sueli Carneiro; Pólen.

Andrade, C. D. de. (1930). Drumond: 100 anos. Belo Horizonte: Alguma Poesia.

Assis, A. S. F. de. (2019). Não pense, mas olhe! Os cotistas negros. (Dissertação de Mestrado). Universidade Federal de Rondônia, Porto Velho, RO, Brasil. http:// Www.mepe.unir.br/uploads/91341742/arquivos/DISSERTA______ANDRELIZE_345083648.pdf

Bento, M. A. S. (2002). Branqueamento e branquitude no Brasil. In M. A. S. Bento \& I. Carone (Orgs.). Psicologia Social do racismo - Estudos sobre branquitude e branqueamento no Brasil. Petrópolis, RJ: Vozes.

Brasil. (2004). Diretrizes Curriculares Nacionais para a Educação das Relações Étnico-Raciais e para o Ensino de História e Cultura Afro-Brasileira e Africana. Brasilia: SECAD/ME.

Derrida, J. (1971). A escritura e a diferença. São Paulo: Perspectivas.

Farias, K. S. C. dos S. (2019). Educar é preciso. Colonizar não é preciso! Afinal, tudo vale a pena se a alma não é PEQUENA. UNIR. (não publicado).
Farias, K. S. C. dos S., \& Moura, A. R. L. (2019). Formação de professores de matemática na amazônia: jogos de cenas desenham construções criativas com Wittgenstein, Derrida e Nietzsche. Imagens Da Educação, 9(2), 78-92. https://doi.org/10.4025/imagenseduc.vgi2.445.95

Freire, P. (2000). Pedagogia da Indignação: Cartas pedagógicas e outros escritos. São Paulo: UNESP.

Guimarães, A. S. (2002). A. Classes, raça e democracia. São Paulo: Editora 34

Instituto Brasileiro de Geografia e Estatística. (2019). Desigualdades sociais por cor ou raça no Brasil. Estudos e Pesquisas: Informação Demográfica e Socioeconômica, 41, 1-12. Rio de Janeiro, RJ: IBGE: Recuperado de https://biblioteca.ibge.gov.br/visualizacao/livros/ Liv101681_informativo.pdf

Jesus Júnior, A. G. de. (2003). Estudos sobre branquitude e branqueamento no Brasil. Psico-USF, 8 (2), 215-216. https://doi.org/10.1590/S1413-82712003000200014

Maldonado-Torres, N. (2007). Sobre la colonialidad del ser: contribuciones al desarrollo de un concepto. In Castro-Gómez, S., \& Grosfoguel, R. (Orgs.), El giro decolonial: Reflexiones para una diversidad epistémica más allá del capitalismo global. (pp. 127-167). Bogotá Colômbia: Siglo del Hombre Editores \& Universidad Central, Instituto de Estudios Sociales Contemporáneos, Pontificia Universidad Javeriana, Instituto Pensar.

Marim, M. M. B., \& Farias, K. S. C. dos S. (2017). Traços vivos: jogos de cenas nas (im)possiveis dobras da escrita na pesquisa em educação (Matemática). Revista Exitus, 7(2), 173-190. https://doi.org/10.24065/ 2237-9460.2017v7n2ID306

Miguel, A. (2015). A Terapia Gramatical-Desconstrucionista como Atitude de Pesquisa (Historiográfica) em Educação (Matemática). Perspectivas Da Educação Matemática, 8(18). Recuperado de https://periodicos. ufms.br/index.php/pedmat/article/view/1466

Munanga, K. (Org.). (2005). Superando o racismo na escola (2. ed. rev.). Brasilia: Ministério da Educação.

Muniz, V. C. (2019, 24 de maio). Em políticas públicas "não basta não ser racista, é necessário ser antirracista". Justificando: Mentes inquietas pensam Direito. Recuperado de http://www.justificando.com/2019/05/24/ em-politicas-publicas-nao-basta-nao-ser-racista-e-necessario-ser-antirracista

Mustapha, Chérif. (2013). O islã e o Ocidente: um encontro com Jacques Derrida. Belo Horizonte: Editora UFMG.

Ribeiro, D. (2017). O que é lugar de fala? Belo Horizonte: Letramento.

Ribeiro, D. (2018). "O racismo é uma problemática branca", diz Grada Kilomba. In D. Ribeiro. Quem tem medo do Feminismo Negro? São Paulo: Companhia das Letras.

Schwarcz, L. M. (2018). Teorias Raciais. In L. M. Schawarz \& F. S. Gomes (Orgs.). Dicionário da Escravidão e Liberdade: 50 textos críticos. São Paulo: Companhia das Letras.

Sartre, J-P. (1968). Reflexões sobre o racismo. São Paulo: Difusão Europeia do Livro. 
Silva, M. D. da. (2010). Educação Ideologia e Complexidade: contribuição para a critica ao pensamento de Edgar Morin e sua interface com a educação brasileira. (Tese de Doutorado). Universidade Estadual de Campinas, Campinas, SP, Brasil. http://repositorio.unicamp.br/bitstream/ REPOSIP/251461/1/Silva_MarceloDonizeteda_D.pdf

Silvério, V. R. (2002). Sons negros com ruídos brancos. In Seyferth, G. et al., Racismo no Brasil. (pp. 89-104). São Paulo: ABONG.

Silvério, V. R. (2003). O papel das ações afirmativas em contextos racializados: algumas anotações sobre o debate brasileiro. In Petronilha, B. G. S., \& Silvério, V. R. (Orgs.), Educação e Ações Afirmativas: entre a injustiça simbólica e a injustiça econômica. (pp. 55-77). Brasília: INEP/MEC

Tamayo-Osorio, C. (2017). Veni vamos hamacar el mundo, hasta que te assustes: uma terapia do desejo de escolarização moderna. (Tese de Doutorado). Universidade Estadual de Campinas, Campinas, SP, Brasil. http://repositorio.unicamp.br/jspui/bitstream/REPOSIP/325354/1/Osorio_CarolinaTamayo_D.pdf.

Tubino, F. (2005, 1 ago.). La interculturalidad critica como proyecto ético-político. In Anais, 1 Encuentro continental de educadores agustinos. Lima, Peru: Organización de Augustinos de América Latina. Recuperado de http://oala.villanova.edu/congresos/educación/ lima-ponen-02.html

Veiga-Neto, A. (2001a, nov.). Incluir para saber: Saber para excluir. Pro-posições, 12(2), 22-31. Recuperado de https://www.fe.unicamp.br/pf-fe/publicacao/2107/ 3536-dossie-veiga-netoa.pdf

Veiga-Neto, A. (2001b). Incluir para excluir. In Larrosa, J., \& Skliar, C. (Orgs.), Habitantes de Babel: poílicas e poéticas da diferença (pp. 105-118). Belo Horizonte, MG: Autêntica.

Veiga-Neto, A. (2003). Faces da diferença. [Entrevista cedida al Gilka Girandello. Pontos de Vista, 5. https:// periodicos.ufsc.br/index.php/pontodevista/article/ view/1252/1661

Walsh, C. (2009). Interculturalidade Critica e Pedagogia Decolonial: In-Surgir, Re-Existir e Re-Viver. In Candau, V. M. F. (Org.), Educação Intercultural na América Latina: entre concepções, tensões e propostas (pp. 12-42). Rio de janeiro: 7 Letras.

Wittgenstein, L. (2014). Investigações filosóficas (9. ed.) Petrópolis: Vozes.

\section{Andrelize Schabo Ferreira de Assis}

Doutoranda em Educação Escolar pela Fundação Universidade Federal de Rondônia (UNIR), em Porto Velho, RO, Brasil; revisora de textos no Instituto Federal de Rondônia (IFRO), em Porto Velho, RO, Brasil.
Doutora em Educação pela Faculdade de Educação da Universidade Estadual de Campinas (Unicamp), em Campinas, SP, Brasil; professora na Fundação Universidade Federal de Rondônia (UNIR), em Porto Velho, RO, Brasil.

\section{Endereço para correspondência}

Andrelize Schabo Ferreira de Assis

Condomínio Pinhais 2

Av. Vigésima, 6134

Rio Madeira, 76821-436

Porto Velho, RO, Brasil 